\title{
Czynniki pobudzające granulopoezę nie są nadużywane w systemowym leczeniu onkologicznym (G-CSF)
}

\author{
Joanna Połowinczak-Przybyłek ${ }^{1}$, Piotr Potemski ${ }^{2}$
}

„Nadużywać" oznacza używać czegoś w nadmiernych, zwykle szkodliwych dla zdrowia ilościach lub wykorzystywać w niewłaściwy sposób. Zarówno zapisy odpowiednich charakterystyk produktów leczniczych, jak i aktualne rekomendacje towarzystw naukowych pozwalają na bardzo szerokie stosowanie czynników wzrostu granulocytów w pierwotnej profilaktyce gorączki neutropenicznej. Badania, w których oceniano codzienną praktykę lekarską dotyczącą użycia G-CSF, wskazują na dobrą zgodność z zaleceniami. Jednak niektóre wskazania do pierwotnej profilaktyki wymieniane w obecnych zaleceniach budzą kontrowersje, a ryzyko wystąpienia gorączki neutropenicznej wydaje się zawyżone. Na przykład rekomendacje EORTC wskazują, że schemat M-VAC wiąże się ryzykiem gorączki neutropenicznej wynoszącym aż 26\% i dlatego pierwotna profilaktyka jest konieczna. W badaniu III fazy porównującym skojarzenie cisplatyny i gemcytabiny do schematu M-VAC ryzyko to wyniosło tylko $14 \%$. Z tego powodu pewne zmiany w treści obecnych rekomendacji wydają się być zasadne.

\section{Disadvantage of overuse of granulocyte-colony stimulating factors (G-CSF) in systematic anticancer treatment}

To overuse means to use something too much, usually in a way that is deleterious to health or to use something improperly. Both respective summaries of product characteristics and current recommendations prepared by various scientific societies support very wide usage of granulocyte-colony stimulating factors in primary prophylaxis of febrile neutropenia. Studies that evaluated common practice in usage of G-CSFs confirmed good agreement with recommendations. However, some indications for primary prophylaxis listed in current guidelines are controversial as the risk neutropenic fever seems to be overestimated. For example, EORTC guidelines indicate that the M-VAC regimen is associated with the risk of neutropenic fever as high as $26 \%$ and primary prophylaxis is mandatory. In a phase III trial that compared M-VAC with combination of cisplatin and gemcitabine it was only $14 \%$. Thus, some changes in current guidelines seem to be warranted.

NOWOTWORY Journal of Oncology 2015; 65, 6: 535-538

Słowa kluczowe: czynniki pobudzające granulopoezę - nadużywanie, pierwotna profilaktyka, rekomendacje Key words: gruanulocyte-colony stimulating factors, primary prophylaxis overuse

\section{Wstęp}

Neutropenia to najczęstsza cytopenia występująca w różnym stopniu nawet u $80 \%$ chorych poddawanych chemioterapii. Jest jednym z najważniejszych czynników predysponujących do wystąpienia zakażeń, gorączki neutro- penicznej (GN) i jej powikłań. Nawet bezobjawowa neutropenia może prowadzić do zmniejszenia intensywności leczenia, co w niektórych sytuacjach (np. leczenie uzupełniające) wiąże się ze zmniejszeniem jego skuteczności. Istotne jest zatem odpowiednie postępowanie minimalizujące ryzyko

\footnotetext{
${ }^{1}$ NU-MED Centrum Diagnostyki i Terapii Onkologicznej w Tomaszowie Mazowieckim

${ }^{2}$ Uniwersytet Medyczny w Lodzi

Wojewódzki Szpital Specjalistyczny im. M. Kopernika w Łodzi
} 
wystąpienia neutropenii, a zwłaszcza jej niekorzystnych następstw.Wprowadzenie do powszechnego użycia czynników pobudzających granulopoezę (G-CSF, granulocyte-colony stimulating factors) ułatwiło realizację tych założeń. Szybko jednak pojawiły się wątpliwości dotyczące możliwości nadużywania tych leków w codziennej praktyce lekarskiej.

\section{Pojęcie nadużywania w świetle definicji słownika PWN}

Słownik PWN definiuje nadużywanie jako używanie czegoś w nadmiernych, zwykle szkodliwych dla zdrowia ilościach lub wykorzystywanie czegoś w niewłaściwy sposób [1]. Czy w Polsce w systemowym leczeniu onkologicznym G-CSF są wykorzystywane w nadmiernych, szkodliwych dla zdrowia ilościach? Czy może stosowane są niezgodnie z Charakterystyką Produktu Leczniczego (CHPL) lub sprzecznie z zaleceniami odpowiednich towarzystw naukowych? Charakterystyki produktu leczniczego zarówno filgrastymu, jak i pegfilgrastymu pozwalają na bardzo liberalne użycie tych leków [2]. Obie substancje można m.in. stosować w celu skrócenia czasu trwania neutropenii i zmniejszenia częstości występowania gorączki neutropenicznej u pacjentów otrzymujących chemioterapię lekami cytotoksycznymi z powodu stwierdzonego nowotworu złośliwego (z wyjątkiem przewlekłej białaczki szpikowej i zespołów mielodysplastycznych). Ponadto filgrastym podawany jest w celu skrócenia czasu trwania neutropenii u pacjentów poddanych leczeniu mieloablacyjnemu przed przeszczepieniem szpiku, jeśli istnieje zwiększone ryzyko przedłużonej, ciężkiej neutropenii $[3,4]$. Opierając się na samych zapisach CHPL, właściwie nie sposób wyznaczyć granic, których przekroczenie oznaczałoby nadużycie.

\section{Zalecenia towarzystw naukowych i rekomendacje ekspertów}

Zalecenia towarzystw naukowych i rekomendacje ekspertów są bardziej restrykcyjne. Obserwacje dotyczące znacznych rozbieżności opinii wśród klinicystów odnośnie zasad stosowania G-CSF oraz pojawiające się wciąż nowe publikacje o skuteczności granulopoetyn, ich wpływie na ostateczne wyniki leczenia chorych i toksyczność prowadzonej terapii doprowadziły do wypracowania kilkukrotnie już modyfikowanych rekomendacji najważniejszych towarzystw naukowych i grup ekspertów, m.in. PTOK, ASCO, NCCN, ESMO, EORTC. Zalecenia te porządkują i ograniczają wskazania do terapii czynnikami pobudzającymi granulopoezę w stosunku do szerokich wskazań rejestracyjnych dla tych leków. Zwracają uwagę na znaczenie podawania G-CSF głównie w profilaktyce pierwotnej, jak i wtórnej - w celu zmniejszenia ryzyka wystąpienia GN i jej powikłań, a także utrzymania odpowiednich dawek i rytmu chemioterapii w leczeniu radykalnym i w przypadkach, gdy leczenie systemowe istotnie wpływa na czas przeżycia chorych. Znacząco ograniczają też wykorzystywanie G-CSF w terapii GN. Mimo pewnych różnic pomiędzy wytycznymi różnych towarzystw naukowych - wszystkie podkreślają, że standardowe profilaktyczne użycie czynników pobudzających granulopoezę powinno być ograniczone do pacjentów z dużym ryzykiem wystąpienia GN (20\% lub więcej) oraz kilku innych specjalnych sytuacji klinicznych [3-6]. W przypadku profilaktyki pierwotnej jest to np. współistnienie infekcji wirusem HIV, w przypadku profilaktyki wtórnej - konieczność utrzymania należytych dawek i rytmu podawania chemioterapii u pacjentów, u których redukcja dawki lub wydłużanie czasu leczenia w następstwie neutropenii mogą wpłynąć na zmniejszenie skuteczności terapii i pogorszenie rokowania. Ograniczenia te wynikają z obserwacji, że mimo dużej liczby neutropenii - w przypadku standardowo prowadzonej chemioterapii o mniejszym ryzyku GN — rzeczywista ilość poważnych i zagrażających życiu powikłań neutropenii jest mała. Próg ryzyka 20\% został wyznaczony na podstawie wyników dwóch ważnych badań klinicznych, wskazujących na znaczące zmniejszenie ryzyka wystąpienia GN dzięki zastosowaniu profilaktyki G-CSF $[7,8]$.

Podstawowym czynnikiem wpływającym na ryzyko GN jest rodzaj stosowanej chemioterapii, jednak powiązanie ryzyka gorączki z poszczególnymi schematami jest trudne. W przeprowadzonych badaniach ryzyko to różniło się czasem znacząco pomiędzy poszczególnymi pacjentami otrzymującymi ten sam rodzaj chemioterapii, zależnie od indywidualnych czynników związanych z chorym (np. w przypadku chemioterapii AC $\rightarrow$ docetaksel wynosiło 5\%-25\%) [5, 6]. Pomimo tego zróżnicowania udało się wyodrębnić pewne schematy, których stosowanie w istotny sposób wiąże się ze zwiększonym ryzykiem wystąpienia GN i jej powikłań. Należą do nich m.in.: schemat TAC u chorych na raka piersi czy topotekan u chorych na drobnokomórkowego raka płuca [6]. Uwzględniając wpływ cech zależnych od samego pacjenta na ryzyko wystąpienia GN, ASCO i NCCN zalecają, by oceniając ogólne ryzyko gorączki neutropenicznej poza rodzajem chemioterapii i typem nowotworu, uwzględnić dodatkowo inne czynniki, takie jak: wiek powyżej 65 r.ż., zaawansowanie choroby, zaburzenia czynności wątroby i nerek, współistniejące choroby układu krążenia oraz inne choroby dodatkowe, niezagojone rany i niedawno przebyty zabieg chirurgiczny, zły stan odżywienia i sprawności chorego, wcześniejszą chemio- i radioterapię, zajęcie szpiku kostnego przez nowotwór oraz wcześniejsze neutropenie i infekcje [4, 5]. W zaleceniach EORTC z 2011 r. zawarty jest algorytm postępowania uwzględniający różne czynniki decydujące o zastosowaniu profilaktyki pierwotnej.W przypadku schematów, dla których oszacowane ryzyko GN wynosi pomiędzy 10 a 20\%, zalecana jest ocena uwzględniająca inne czynniki zwiększające to ryzyko, takie jak: wiek powyżej 65 r.ż., duże zaawansowanie choroby nowotworowej, GN w wywiadzie, brak profilaktyki antybiotykowej, płeć żeńska, 
współistniejące zaburzenia czynności nerek i wątroby oraz układu krążenia, zły stan odżywienia i sprawności ogólnej oraz stężenie hemoglobiny $<12 \mathrm{~g} / \mathrm{dl}$ [6].

\section{Badania oceniające stosowanie wytycznych w praktyce klinicznej we Francji i Wielkiej Brytanii}

W 2010 roku ukazały się wyniki badania oceniającego stosowanie G-CSF w praktyce klinicznej wśród 990 pacjentów we Francji przed (1999 r.) i po ukazaniu się wytycznych EORTC i ASCO (lata 2006-2007). Stwierdzono w nich 69-procentową zgodność użycia G-CSF z wytycznymi, choć zdarzały się nawet przypadki podawania G-CSF jednocześnie z chemioterapią. Zaobserwowano również istotny statystycznie wzrost częstości stosowania czynników w ramach profilaktyki pierwotnej i w pierwszej linii leczenia, a zmniejszenie w profilaktyce wtórnej i w kolejnych liniach chemioterapii [9].

Podobnemu audytowi poprawności stosowania G-CSF poddano pacjentów leczonych w okresie kwiecień-maj 2008 r. w St. Thomas' Hospital w Londynie. G-CSF zastosowano tam w 104 przypadkach, z czego u 55\% w ramach profilaktyki pierwotnej. Większość, bo $66 \%$ chorych była leczona z założeniem radykalnym. Zgodność z wytycznymi wynosiła $72 \%$ [10].

\section{Stosowanie czynników wzrostu w praktyce klinicznej polskich onkologów}

W ramach projektu GoPractice oceniono znajomość wytycznych dotyczących profilaktyki wtórnej G-CSF wśród 169 polskich onkologów pochodzących z różnych ośrodków w siedmiu regionach naszego kraju. Odpowiedzi na pytania kwestionariusza zawierającego siedem różnych pod względem typu nowotworu, charakterystyki pacjentów i rodzaju chemioterapii przypadków klinicznych w prawie $90 \%$ pokrywały się z zaleceniami PTOK i EORTC. Zdecydowanie gorzej wypadła ocena prawidłowości postępowania w przypadku leczenia pacjentów z GN: aż 52\% respondentów opowiedziało się za użyciem czynników wzrostu, co było sprzeczne $z$ rekomendacjami [11].

\section{Wskazania refundacyjne NFZ}

Zalecenia towarzystw naukowych zawężające stosowanie czynników pobudzających granulopoezę w stosunku do wskazań rejestracyjnych oraz czynniki ekonomiczne znalazły odzwierciedlenie także we wskazaniach refundacyjnych polskiego płatnika (NFZ). Stanowi to dodatkowy czynnik ograniczający możliwość nadużywania G-CSF w ramach profilaktyki pierwotnej w Polsce. NFZ za uzasadnioną uznaje profilaktykę pierwotną z użyciem G-CSF jedynie u pacjentów z grupy dużego ryzyka gorączki neutropenicznej ( $\geq 20 \%$ ), uwzględniając także czynniki zwiększające ryzyko związane z pacjentem zawarte w wytycznych ASCO i NCCN [12].

\section{Czy zastosowanie pierwotnej profilaktyki G-CSF będzie nadużyciem w świetle zaleceń towarzystw naukowych? Wybrane przypadki kliniczne}

Zawężenie grupy pacjentów, u których w świetle zaleceń można stosować profilaktykę pierwotną G-CSF wyłącznie do przypadków z ryzykiem wystąpienia GN wynoszącym co najmniej 20\%, teoretycznie mogłoby sprzyjać nadużyciom. W praktyce klinicznej (jak wynika również z głosowania słuchaczy podczas debaty) skłonność do stosowania G-CSF jest nawet mniejsza niż możliwości stwarzane przez zalecenia. 50-letni mężczyzna chory na raka pęcherza moczowego z przerzutami do płuc, w stanie sprawności PSO, bez utraty masy ciała, ma w świetle zaleceń EORTC wskazania do profilaktyki pierwotnej podczas chemioterapii M-VAC, ponieważ szacowane ryzyko GN w tym przypadku wynosi $26 \%$ [6]. Podobnie 40-letnia chora na płaskonabłonkowego raka szyjki macicy w IV st. zaawansowania, PS0, leczona cisplatyną z paklitakselem — ryzyko GN wynosi $28 \%$ [6]. Również u 66-letniej kobiety chorej na DLBCL w stadium zaawansowania IIA, PSO, zgodnie z rekomendacją ESMO (u osób leczonych radykalnie CHOP lub R-CHOP od 65 r. ż.) zalecana jest pierwotna profilaktyka G-CSF [3]. Także u 46-letniej kobiety z miejscowo zaawansowanym rakiem piersi cT3cN2cM0, leczonej $4 \times A C$, a następnie $4 \times$ docetakselem, szacowane ryzyko GN dochodzące do $25 \%$ upoważnia do zastosowania profilaktyki pierwotnej [6]. Nawet w przypadku stosowania chemioterapii FOLFIRI (podczas której ryzyko GN związanej ze schematem szacuje się na 3\%-14\% ) u 68-letniej kobiety z rakiem jelita grubego w IV st. zaawansowania, PS1, prawidłowe jest - w świetle zaleceń — włączenie profilaktyki pierwotnej ze względu na obecność 2 czynników zwiększających ryzyko wystąpienia gorączki [6].

Jak ilustrują powyższe przykłady, mimo wprowadzenia ograniczeń profilaktycznego stosowania czynników pobudzających granulopoezę rekomendacje towarzystw naukowych i grup ekspertów dają w rzeczywistości możliwości leczenia zgodne z wytycznymi szerokiej grupy pacjentów i bardzo małe ryzyko nadużyć w świetle definicji tego pojęcia.

\section{Stopień wiarygodności danych wykorzystanych w tworzeniu zaleceń}

Należy jednak pamiętać, że cytowane zalecenia zostały opracowane na podstawie danych pochodzących z artykułów publikujących wyniki badań klinicznych II, III i IV fazy, prospektywnych badań obserwacyjnych, zaleceń, metaanaliz oraz przeglądów systematycznych. Często celem badań wykorzystanych do utworzenia zaleceń nie była ocena ryzyka wystąpienia GN, a np. ustalenie wartości nowego sposobu leczenia. Stąd istnieją duże rozbieżności pomiędzy poszczególnymi badaniami zarówno w definicji GN, jak i w ocenie ryzyka jej wystąpienia związanego 
z poszczególnymi schematami chemioterapii. Często jako podstawę tworzenia zaleceń przyjmowano wyniki badań Il fazy pomimo tego, że dostępne były także wyniki badań III fazy, będące bardziej wiarygodnym źródłem informacji o częstości występowania GN. Dobrym przykładem może być wykorzystywany u chorych na zaawansowanego raka z komórek przejściowych schemat M-VAC. Zalecenia EORTC wskazują na konieczność zastosowania pierwotnej profilaktyki G-CSF (ryzyko GN 26\%), podczas gdy badanie III fazy, w którym schematu M-VAC używano u chorych w grupie kontrolnej, wskazywało na ryzyko GN wynoszące tylko 14\% [13]. Różne były także populacje pacjentów włączane do badań klinicznych. W części badań profilaktyka antybiotykami była elementem protokołu badania, w innych brakuje na ten temat informacji. Wiele z czynników zwiększających ryzyko wystąpienia GN zostało wyodrębnionych na podstawie danych jedynie trzeciego stopnia wiarygodności, pochodzących z badań klinicznych bez randomizacji. Te czynniki to np. płeć żeńska, zły stan odżywienia i sprawności ogólnej, zaburzenia czynności nerek i wątroby $[5,6]$.

\section{Podsumowanie}

Aktualne rekomendacje (zwłaszcza EORTC) pozwalają na szerokie stosowanie G-CSF zarówno w profilaktyce pierwotnej, jak i wtórnej. Opieranie się w niektórych rekomendacjach na wynikach badań II, a nie III fazy w określaniu ryzyka wystąpienia GN powoduje, że pewne zmiany w treści obecnych rekomendacji wydają się być zasadne. Znajomość zasad stosowania G-CSF w profilaktyce pierwotnej wśród polskich onkologów jest dobra, co potwierdzają wyniki badania oceniającego zgodność kwalifikacji do profilaktyki wtórnej z zaleceniami PTOK i EORTC. Dodatkowym czynnikiem skutecznie ograniczającym i tak już realnie niewielką możliwość nadużywania czynników stymulujących granulopoezę w praktyce klinicznej jest konieczność przestrzegania wskazań do refundacji określonych przez polskiego płatnika.

Dr hab. n. med. Piotr Potemski, prof. nadzw.

Uniwersytet Medyczny w Łodzi

Wojewódzki Szpital Specjalistyczny im. M. Kopernika w Łodzi

ul. Pabianicka 62, 93-513 Łódź

e-mail:piotrpo@mp.pl

Otrzymano i przyjęto do druku: 8 października 2015

Na podstawie wystąpienia podczas III Konferencji Naukowej czasopisma Nowotwory „Debaty onkologiczne”, 10-11 kwietnia 2015 roku.

\section{Piśmiennictwo}

1. http://sjp.pwn.pl (dostęp 30.09.2015).

2. Neupogen. Charakterystyka produktu leczniczego. http://www.leki. urpl.gov.pl (dostęp 30.09.2015).

3. Crawford J, Caserta C, Roila F. Hematopoietic growth factors: ESMO Clinical Practice Guidelines for the applications. Ann Oncol 2010; 21 (Supl. 5): v248-v251.

4. Smith TJ, Bohlke K, Lyman GH i wsp. Recommendations for the Use of WBC Growth Factors: American Society of Clinical Oncology Clinical Practice Guideline Update. J Clin Oncol 2015; 33: 3199-3212.

5. NCCN Clinical Practice Guidelines in Oncology (NCCN Guidelines) Myeloid Growth Factors; http://www.nccn.org/professionals/physician_gls/PDF/myeloid_growth.pdf (dostęp 30.08.2015).

6. Aapro M, Bohlius J, Cameron DA i wsp. 2010 update of EORTC guidelines for the use of granulocyte-colony stimulating factor to reduce the incidence of chemotherapy-induced febrile neutropenia in adult patients with lymphoproliferative disorders and solid tumours. Eur J Cancer 2011; 47: 8-32.

7. Vogel CL, Wojtukiewicz MZ, Carroll RR i wsp. First and subsequent cycle used of pegfilgrastim prevents febrile neutropenia in patients with breast cancer; a multicenter, double-blind, placebo controlled phase III study. J Clin Oncol 2005; 23: 1178-1184.

8. Pfreundschuh M, Trümper L, Kloess M i wsp. Two-weekly or 3-weekly CHOP chemotherapy with or without etoposide for the treatment of elderly patients with aggressive lymphomas: results of the NHL-B2 trial of the DSHNHL. Blood 2004; 104: 634-641.

9. Falandry C, Campone M, Cartron G i wsp. Trend in G-CSF use in 990 patients after EORTC and ASCO guidelines. Eur J Cancer 2010; 46: 2389-2398.

10. Pérez Velasco R. Granulocyte colony-stimulating factor use in a large British hospital: comparison with published experience. Pharm Pract 2010; 8: 213-219.

11. Wojtukiewicz M, Chmielowska E, Filipczyk-Cisarż E i wsp. Clinical practice in secondary prophylaxis and management of febrile neutropenia in Poland: results of the febrile neutropenia awareness project. Contemp Oncol 2014; 18: 425-428.

12. List informacyjny Prezesa Narodowego Funduszu Zdrowia do dyrektorów oddziałów wojewódzkich z dnia 21.02.2012.

13. von der Maase H, Hansen SW, Roberts JT i wsp. Gemcitabine and cisplatin versus methotrexate, vinblastine, doxorubicin, and cisplatin in advanced or metastatic bladder cancer: results of a large, randomized, multinational, multicenter, phase III study. J Clin Oncol 2000; 18: 3068-3077. 